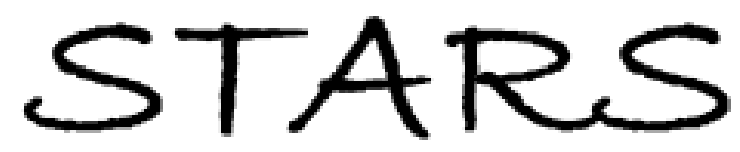

University of Central Florida

STARS

Faculty Bibliography 2000s

Faculty Bibliography

$1-1-2008$

\title{
Improving presence theory through experiential design
}

\author{
Dustin B. Chertoff \\ University of Central Florida \\ Sae Lynne Schatz \\ University of Central Florida \\ Rudy McDaniel \\ University of Central Florida \\ Clint A. Bowers \\ University of Central Florida
}

Find similar works at: https://stars.library.ucf.edu/facultybib2000 University of Central Florida Libraries http://library.ucf.edu

This Article is brought to you for free and open access by the Faculty Bibliography at STARS. It has been accepted for inclusion in Faculty Bibliography 2000 s by an authorized administrator of STARS. For more information, please contact STARS@ucf.edu.

\section{Recommended Citation}

Chertoff, Dustin B.; Schatz, Sae Lynne; McDaniel, Rudy; and Bowers, Clint A., "Improving presence theory through experiential design" (2008). Faculty Bibliography 2000s. 219.

https://stars.library.ucf.edu/facultybib2000/219

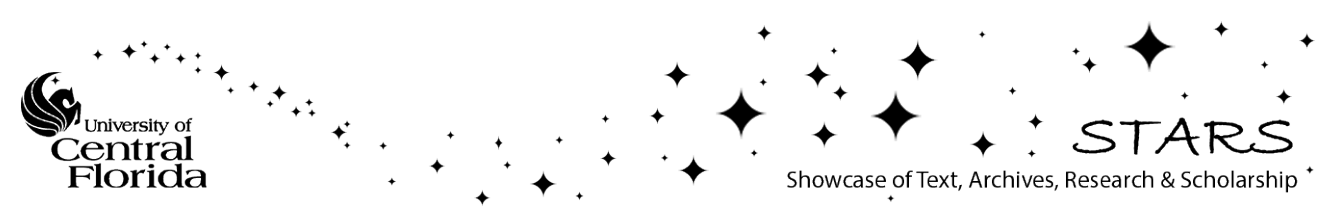




\section{Dustin B. Chertoff*}

Institute for Simulation and Training

University of Central Florida

3280 Progress Drive

Orlando, FL 32826

\section{Sae Lynne Schatz}

Rudy McDaniel

Clint A. Bowers

Department of Digital Media

University of Central Florida

Orlando, FL 32826
Presence, Vol. 17, No. 4, August 2008, 405-413

(๑) 2008 by the Massachusetts Institute of Technology

\section{Improving Presence Theory \\ Through Experiential Design}

\begin{abstract}
Despite ongoing research over the last 15 years, the presence construct remains somewhat limited in its ability to be applied beyond the sensory domain. In order to increase its usefulness for applied challenges (e.g., using presence theory to enhance simulators' effectiveness), a discussion about a new conceptualization of presence is introduced. This novel perspective on presence is rooted in the notion of "experiential design," an approach businesses use to create strategically compelling and memorable experiences. The paper begins with a brief review of presence and then a description of the concepts of experimental design. Following this, a theoretical model of presence, based upon experimental design, is offered. Using this model, an exploration on the mitigation of breaks in presence is offered (a break in presence occurs when presence fails to be maintained). These ideas are presented in order to improve the likelihood of presence emerging for simulation participants and to enhance interdisciplinary researchers' shared conceptualizations of presence.
\end{abstract}

\section{Introduction}

Presence is often described as a subjective sense of "being there" in an environment (Heeter, 1992). It was later defined by Lombard and Ditton as being the "perceptual illusion of non-mediation" (1997). According to these definitions, presence occurs when a person cannot distinguish between sensory input from a hardware-mediated environment and sensory input from reality, and thus responds to the hardware-mediated input as though it came from the real world. In effect, these definitions describe presence as a problem of restricting perception to only the mediated environment.

Many factors are theoretically believed to be causally related to presence. In a recent article, Lee listed the findings from more than 30 presence articles that address causal factors that are "either empirically identified or theoretically argued" to be "closely associated with" presence (Lee, 2004, p. 495). He lists 25 factors, ranging from the participant's mood to the image resolution of the simulator, that affect presence. It is important to note that Lee's review was not intended to be comprehensive; however, its concise presentation effectively demonstrates one of the challenges of presence research. Namely, a categorization system is needed to better understand, and make use of, the many disparate factors that influence presence. (For additional reviews of models of pres-

\footnotetext{
${ }^{*}$ Correspondence to dchertoff@gmail.com.
} 
ence see Sacau, Gouveia, Ribeiro, Gouveia, \& Biocca, 2003; IJsselsteijn \& Riva, 2003; Schuemie, van der Straaten, Krijin, \& van der Mast, 2001; and Draper, Kaber, \& Usher, 1998.)

Given the diversity of sensory stimuli that may influence presence, it is no surprise that researchers have looked at existing models of perception to see how they fit with mediated environments. Mantovani and Riva (1999) describe how Gibson's ecological model of perception can be applied to presence. In the model, a feedback loop exists whereby an organism acts in some manner that will have an effect upon an environment, and in response to organisms, the environment acts in some way so as to have an effect on other organisms. Perception in such a system is the manner that one organism uses its individual ontology to identify available resources from the environment and to then act upon the environment. The environment does not provide a unique marker for each individual. Uniform information, or an affordance, is available to any organism acting in a manner where this information would be required. Depending on the organism and how it acts, these affordances will be interpreted differently. Thus, affordances rely heavily on context.

In an earlier attempt to correspond Gibson's model with presence, Zahoric and Jenison state that "presence is tantamount to successfully supported action in the environment" (1998). A virtual environment will carry within it affordances that the user will interpret in some manner depending on his or her goals within the VE. This realization is important for the design of virtual environments, as the design goal becomes less about environmental realism, and more about environmental support of the desired user behavior.

Witmer and Singer address the complexity of presence by splitting it into the subjective levels of involvement and immersion a participant feels inside a simulated environment (Witmer \& Singer, 1998). Immersion measures the fidelity of the perceptual information coming to the senses and is dictated by the hardware capabilities of the system. Involvement defines the ability of the environment to construct a convincing and relevant experience based on the sensory information to the user. This view was influenced by Fontaine (1992), who described presence as a degree of focus.
Thus, presence should be concerned not only with maintaining the immersive capabilities of the system, but also with the ability of the environment to correspond to the immersive experience the hardware inherently provides.

Zahoric and Jenison's, Witmer and Singer's, and Lee's review are included here to help illustrate one of the problems inherent with today's presence research. As yet, there is no suitable, agreed-upon framework with which to conceptualize our knowledge of presence. While a common operational understanding of presence has emerged from the vast number of studies on contributing factors, there is less agreement on a model for why presence emerges. Given the range of perspectives and disciplines considering this construct, there may never be a universally-accepted definition. However, without such a model, we are less able to effectively advance our understanding, or improve our utilization, of these known contributing factors.

\section{Information-centric versus Knowledge- centric Design}

Existing models of presence are useful but restricted. They suffer from two limitations. First, many models tend to focus heavily on perceptual issues while focusing less attention other facets of virtual experiences, such as cognition and emotion. However, recently, there has been an encouraging trend to further study cognitive factors (e.g., Sas \& O'Hare, 2005; Nunez, 2003). Second, as mentioned above, these models fail to provide an interpretable, extensible framework with which to understand and apply the theoretical principles to practical applications.

To better conceptualize these limitations, researchers should consider the relationship between information and knowledge. Data, information, and knowledge are often defined in a hierarchical relationship, where data consist of the least complex structures and knowledge the most complex ones. Data are discrete facts, figures, or even unassimilated raw observations (Davenport \& Prusak, 1997). Information is structured data, and at the highest level, knowledge is structured, abstracted, and transitive information. In other words, knowledge is 
"the link people make between information and its potential applications" (Baker \& Badamshina, 2002, p. 7). Current virtual environments are primarily conceptualized as information technologies, while they should instead be considered "knowledge technologies."

This relationship between information and knowledge lies at the heart of Gestalt psychology. Nearly a century ago, Gestalt theorists realized that an experience is greater than the sum of its parts. That is, people contrive knowledge about their experiences "beyond the information given" (Bruner, 1973). This realization helped lead to our understanding of schema theory (Neisser, 1976), and it has been extended to explain the binding problem, which is "basically, the problem of how the unity of conscious perception is brought about by the distributed activities of the central nervous system" (Revonsuo \& Newman, 1999; this is discussed in more detail later in this paper).

However, the traditional perceptual approach to understanding presence may be considered informationcentric (i.e., primarily concerned with the presentation of data). Instead, effective virtual environments should be considered knowledge systems (i.e., designed so that their inherent information is encapsulated as a holistic experience). Subsequently, virtual environments should be designed with participants' overall experiences in mind, which (according to this analogy) would transform them from information-centric to knowledgecentric systems.

\section{How Do We Design Experiences?}

How can we design a knowledge-centric system? First, it is necessary to consider academic constructs of an experience that may support this purpose. Following that, a discussion of experiential design theories and how they may relate to mediated environments and a holistic model of presence is in order.

\section{I Defining "Experience"}

Forlizzi and Battarbee (2004) offer an in-depth definition of experience; a limited portion of their definition is offered here. They describe an experience as something that can be articulated, named, and schematized within a person's memory. Experiences of this type have beginnings and ends, but anticipation of, and reflection on, the experience may take place before or after the event.

A managed experience is achieved when experiential design is strategically applied to environments or activities in which groups or individuals will interact. Research into managed experiences in virtual spaces - such as online environments, computer-based simulations, or simulation-based training-is limited. The modest number of publications that do consider virtual experiences tend to focus on the consumer experiences of e-commerce portals (e.g., Tscheligi, 2005; Patricio, Falcão e Cunha, Fisk, \& Jardim Nunes, 2004) or distributed communication (e.g., Battarbee, 2003). However, researchers can gain new insight from considering experience design in the context of simulation and training.

\subsection{Experiential Design: A Marketing Approach}

Experiential design is a marketing approach used to craft strategically compelling and memorable encounters. In experiential businesses, the customers pay for the feelings of engaging in the experience, over and above the costs associated with the goods and services alone (Schmitt, 2003). For businesses, the outcome of experiential design is higher earnings; however, it is the process that achieves that outcome that is of interest here.

Experiential designs are successful when they encourage people to create meaningful emotional and social connections - personal narratives that involve episodic memories, and positive associations with the artifacts of that experience (such as a particular product, in marketing terms; Battarbee \& Mattelmäki, 2002). In this model, prior experiences are neither discarded nor ignored as irrelevant, but are rather integrated into the success of a given product. This process could also be advantageously applied to mediated environments in order to achieve greater levels of presence, and by extension, potentially lead to better performance (Barfield, Zeltzer, Sheridan, \& Slater, 1995).

According to Pine and Gilmore (1999), the core of a 
successful experiential business is its ability to create "mass customization," or services that resemble theater, where the staff are actors, the goods are props, and the customer is the star. Schmitt (2003) describes this as connecting with the customer at every touchpoint and integrating different elements of the customer's experience. He uses the term "touchpoint" to refer to any interaction between a customer and the product/company, such as when the customer uses the product, sees an advertisement for the product, or even just talks about it with friends. Experience design is concerned with sales and brand preferences, and providing customers with value- before, during, and after sales - by delivering information, service, and interactions that result in compelling experiences. In order to achieve this, the product or storefront is carefully designed to engage the consumers on five dimensions: physical, cognitive, affective, active, and relational (Pine \& Gilmore).

Presented here is a new multidimensional heuristic that applies Pine and Gilmore's sensory, cognitive, affective, active, and relational dimensions to presence. The sensory dimension includes all sensory input-visual, aural, haptic, and so forth-as well as perception of those stimuli. For simulation, the sensory dimension can be represented through hardware and software (e.g., Sanchez-Vives \& Slater, 2005; Zahorik \& Jenison, 1998; Flach \& Holden, 1998).

The cognitive dimension encompasses all mental engagement with an experience, such as anticipating outcomes and solving mysteries. For simulation, much of the cognitive dimension can be interpreted as task engagement. Note that level of engagement is not necessarily correlated with a simulation's degree of fidelity (e.g., Ma, 2002). Instead, task engagement here is related to the intrinsic motivation, meaningfulness, and continuity (actions yielding expected responses) of an activity.

The affective dimension refers to a participant's emotional state. For simulation, this dimension can be linked to the degree to which a person's emotions in the simulated environment accurately mimic his or her emotional state in the same real-world situation. For example, does a participant feel the same degree of arousal in a dismounted infantry simulation as he or she would in the real-life equivalent?
The active dimension relates to the degree of personal connection a person feels to an experience. Does he or she incorporate the experience into his or her personal narrative; does he or she form meaningful associations via the experience? For simulation, one can associate the active dimension with the degree of empathy, identification, and personal relation a participant feels with the simulation's scenario, environment, and avatars.

The relational dimension is composed of the social aspects of an experience. For simulation, this can be operationalized as co-experience-creating and reinforcing meaning through collaborative experiences (Forlizzi \& Battarbee, 2004; Battarbee, 2003). Experiences that are created or reinforced socially are usually stronger than individual experiences and they further enable individuals to develop personal and memorable narratives (Battarbee, 2003).

\section{Presence and Experience}

What should be clear from Lee's review (2004) is that presence is an emergent factor due to the interaction of many components; in other words, it is a result that is greater than the sum of its parts. These components can be related to experience by following the operationalizations outlined in the previous section. Therefore the goal of the mediated environment designer should not only be creating an environment, but also creating an experience. The purpose of this is twofold.

First, by utilizing experience, a more personal connection to the environment can be achieved. While it remains to be tested through experimentation, it is hoped that such a personal connection would lead to a strengthening of the factors that contribute to the emergence of presence. Existing research data and theories suggest that the elements of presence are highly interconnected (Witmer \& Singer, 1998; Slater, 2002b; Nunez, 2003; Nunez \& Blake, 2003). Thus, one future area of research will be to apply factor analytical methods, in an attempt to validate the experiential construct with empirical data.

Second, strong experiences contribute to new schema being formed, or when possible, new information being 
Table I. Example Causes of Breaks in Presence

\begin{tabular}{|c|c|c|}
\hline Category & Description & Example \\
\hline $\begin{array}{l}\text { External } \\
\text { interference }\end{array}$ & The outside world interferes. & $\begin{array}{l}\text { A participant is engaged with a dismounted-soldier } \\
\text { simulator, but he or she can hear people in the } \\
\text { next room discussing their lunch plans. }\end{array}$ \\
\hline $\begin{array}{l}\text { Internal } \\
\text { interference }\end{array}$ & The internal world interferes. & $\begin{array}{l}\text { A participant is engaged with a computer-based } \\
\text { task trainer, but something distracts him or her, } \\
\text { and he or she begins daydreaming about his or } \\
\text { her upcoming vacation. }\end{array}$ \\
\hline $\begin{array}{r}\text { Inconsistent } \\
\text { mediation }\end{array}$ & $\begin{array}{l}\text { The mediated environment fails to } \\
\text { consistently support its output } \\
\text { message or media. }\end{array}$ & $\begin{array}{l}\text { A participant is engaged in a virtual-flight } \\
\text { simulator, but the program freezes or runs } \\
\text { slowly when there are too many agents onscreen. }\end{array}$ \\
\hline $\begin{array}{l}\text { Contradictory } \\
\text { mediation }\end{array}$ & $\begin{array}{l}\text { The mediated environment } \\
\text { contradicts participants' } \\
\text { established schema. }\end{array}$ & $\begin{array}{l}\text { A participant is engaged with a police simulator. } \\
\text { He or she is tracking a (simulated) suspect } \\
\text { through a building, but he or she is distracted } \\
\text { when trying to open a door that, he or she } \\
\text { learns, he or she cannot interact with because } \\
\text { that area of the building was never programmed. }\end{array}$ \\
\hline $\begin{array}{l}\text { Unrefined } \\
\text { mediation }\end{array}$ & $\begin{array}{l}\text { The mediated environment evokes } \\
\text { too many (potentially- } \\
\text { contradictory) schemas. }\end{array}$ & $\begin{array}{l}\text { A participant is working with a virtual library. Each } \\
\text { attempt to articulate a request for information } \\
\text { returns massive amounts of data, most of which } \\
\text { is irrelevant and atypical of an actual library } \\
\text { experience. (Information overload.) }\end{array}$ \\
\hline
\end{tabular}

added to existing schema. This has an important implication for training environments, since stronger experiences tend to beget better information retrieval.

It is important to note that not all successful VE's are likely to require the same types or degrees of experiential design; instead, different combinations of the experiential dimensions will probably best support different types, or training subjects, of simulations. Once validated, the experiential-presence model can lead to a framework with which to appraise and compare virtual environments. For example, the types (e.g., affective or social) of experiential stimuli the presence contributing factors used can be documented. That combination can then be analyzed for various factors, such as the breaks in presence outlined in Table 1 . With this information, the likelihood of a presence being maintained on a particular set of stimuli can be quantified. This lessens the need for direct participant involvement in the presence- evaluation process and gives simulation designers another way to analyze their success, in terms of presence, before participants are added into the equation.

\section{Breaks in Presence}

An application that can immediately be addressed by this new conceptualization of presence is to examine times when presence is absent; in other words, to define presence by examining its opposite: lack of presence. Slater (2002a) proposes that presence is merely concerned with maintaining the perception of an environment, and that presence is the degree to which the secondary environment overrides awareness of the primary. Thus, presence is achieved when the primary environment is no longer noticeable, and a break in presence (BIP) occurs when a participant attends to the primary 
environment rather than the secondary, mediated one (Slater, 2002a). Refer to Slater et al. (2006) for an explanation of using BIPs and physiological responses to study presence itself.

Following this definition, we suggest that a BIP occurs whenever the participant attends to stimuli that fail to support the message of the secondary environment. This means that breaks in presence can be unintentionally generated from the mediated environment itself if any of its components do not adequately support one another. Essentially, all components of the environment must be carefully designed to ensure that the desired user experience is obtained. In Table 1 , building upon Slater's ideas, we list example categories of presencebreakers and the situations in which they may occur. These observations extend traditional approaches to presence by considering the experiential dimensions of experience that were outlined above.

A BIP due to external interference is induced by the primary environment providing input at a level high enough to be noticed by a user. This could be caused by loud conversation or by the hardware physically interfering with the user performing a task. Such BIPs can be best addressed by utilizing quiet rooms and minimizing the physical side-effects of technology on a user.

Internal interference is probably the most difficult to control, from an experimental design standpoint. It would be caused by the user turning to an internally created environment, rather than attending to the desired mediated one; it is the equivalent of daydreaming. Mitigating such a BIP would require that the mediated environment induce enough involvement of the user so as to prevent attention from drifting.

An obvious example of presence-breaking in virtual environments is found in the case of inconsistent mediation. When a virtual environment is inconsistently mediated, there is not enough fidelity to support the participant's active engagement with the secondary environment in a temporally satisfying fashion. Such BIPs can be particularly jarring when a high-fidelity experience is suddenly transformed into a low one. For example, a participant might be exploring a virtual forest with trees rendered in stunning detail, but when animals or additional avatars wander into the scene, the graphics and audio lag noticeably. At this point in time, the participant is harshly reminded of the secondary environment's dependency on machinery from the primary environment. Issues such as network delay, hardware limitations, or software glitches are primary contributors to this type of disjointedness. This is different from contradictory mediation in that the information being presented by the mediated environment appropriately matched the expectations and schema established over the course of being in the environment.

With contradictory mediation, the provided information fails to match the user's existing schema from the start. There is no familiar experience with which to match the current environment, and BIP occurs while new schema are developed.

In addition to the lack of information in key virtual scenarios, too much information can also lead to BIPs. For example, a participant exploring a multiuser virtual world might find himself or herself unable to immediately assimilate or respond to the myriad demands for attention from other characters, the environment, and objects within that environment. Instead, they first must relocate to a less popular location or otherwise attenuate environmental stimuli to a manageable level. This forces them to attend, at least momentarily, to external cues such as controls or input devices. Information atypical of a given scenario may also be problematic; this type of information is present when an individual's expectations for the secondary environment are not compatible with what is actually occurring within that experience.

In other words, information (sensory, cognitive, or otherwise) that cannot be readily assimilated into a coherent unit of knowledge will often result in "information overload" (Carey \& Kacmar, 1997). Slater hints at this notion when he says that information has to be consistent in order to encourage a greater probability that the correct interpretation for the environment will be selected $(2002 a)$. This is paralleled in the real world in situations where too much information leads to a break in attention (e.g., Yerkes \& Dodson, 1908). This is described in Table 1 as "unrefined mediation," in which virtual stimuli are not fully packaged into forms easily absorbable by human participants.

As our example of unrefined mediation suggests, more information and inputs from the mediated environment are not necessarily advantageous. Even if a vir- 
tual environment encourages presence, it may be lost if participants are forced to focus their attention on absorbing, assimilating, and making sense of conflicting information. This is likely to cause participants to shift their focus away from the mediated environment to their own, internal environment.

This condition also contributes to "the binding problem," which is concerned with how the brain integrates (or fails to integrate) the variety of sensory stimuli into a single, conscious experience (e.g., Fiore \& Salas, 2004). Essentially, individuals' memories, processes, and behaviors are guided by schema, learned cognitive structures used for processing, storing, and manipulating patterns of information (e.g., Schank \& Abelson, 1977; Neisser, 1976). By utilizing the correct combination of schema, it is theorized that a perceptually-limited VE can still facilitate high levels of presence because the information encoded in the schemas will fill in the perceptual gaps (Harvey \& Sanchez-Vives, 2005). In other words, "some minimal set of sensory cues are needed to establish presence in a place ... the mind fills in the gaps" (Slater, 2002b, p. 438).

Researchers have recently studied schema within the context of virtual worlds, specifically in relation to tasks such as memory retrieval and object recognition in virtual environments (Flannery \& Walles, 2003; Mania, Robinson, \& Brandt, 2005). Flannery and Walles explain the difference between schema-consistent versus schema-inconsistent objects, and they demonstrate that individuals react to schema-consistent and schemainconsistent virtual objects in similar manners, regardless of whether the objects are simulated in a virtual world or tangible in real life. However, in virtual environments, participants' overall memory sensitivity and the confidence levels are a little lower, compared to similar real-world situations (Flannery \& Walles).

Since schema represent models of prototypical situations, our brains can use existing schematic information to fill in missing details from new environments or experiences. However, the new stimuli must convey consistent and sufficient information; otherwise, the observer will not be able to match it with an existing mental template. If this occurs, an accurate and complete schematic representation of the new experience will not be realized, resulting in the memory of the new event being poorly encoded and difficult to retrieve at a later time (cf. Hunt \& Ellis, 1974; Mandler, 1980; Tulving, 1983).

Based upon this discussion of schema theory, it may prove more useful to provide less information, but in a more holistic manner that takes advantage of a user's previous experiences, thus triggering a binding that the environment itself could not explicitly create. The creation of virtual environments that include more comprehensive experiential factors, attempts to mitigate BIPs beyond those due to external interference and inconsistent mediation. This process begins by looking at dimensions beyond the heavily studied sensory and cognitive domains (Held \& Durlach, 1992; Sheridan, 1992; Barfield \& Weghorst, 1993; Lombard \& Ditton, 1997; Lombard, Reich, Grabe, Bracken, \& Ditton, 2000). The aim is to integrate the various elements of experience-sensory, cognitive, affective, active (personal), and relational (social) — to construct a model that is capable of eliciting an enhanced sense of presence, and which hopefully will create an ideal situation for developing accurate, memorable, and stable schema.

\section{Conclusion}

Experiential design has the potential to improve the design process of immersive, virtual technologies. By tailoring the process around maintaining a user's experience, factors that otherwise would contribute to BIPs can be mitigated. This also fits with the idea of user-centered design (Gabbard, Hix, \& Swan, 1999), in which usability is incorporated into a product throughout the production process. As users interact with the interface and begin to react with the virtual environment, the designer can shift from one group of factors associated with the experience to another. Once user feedback shows adequate levels of sensory satisfaction and cognition is engaged, for example, the design team can move toward the next task of stimulating cognitive interaction to a level sufficient for active/social behaviors to emerge.

This paper closes with a call to other researchers: begin to explore the holistic experience of participating in mediated environments. As computer science and sen- 
sory technologies continue to advance, we may find that increased processing power and more realistic sensations offer diminishing results in terms of presence. We should begin to look toward the user's internal response to the mediated environment on dimensions other than strictly sensation and cognition. Thus, researchers must better understand the other parts that contribute to the overall virtual experience, namely, the participants' established schema and experiences. By hooking into this yet-untapped resource, we may find some startling results with interesting implications for both measurement and design.

\section{Acknowledgments}

We would like to thank Stephen Fiore for comments and suggestions on an early draft.

\section{References}

Baker, K. A., \& Badamshina, G. M. (2002). Knowledge management. In Management Benchmark Study. Office of Science, Department of Energy. Available at http://www. au.af.mil/au/awc/awcgate/doe/benchmark/.

Barfield, W., \& Weghorst, S. (1993). The sense of presence within virtual environments: A conceptual framework. In G. Salvendy \& M. J. Smith (Eds.), Human-computer interaction: Software and hardware interfaces (pp. 699-704). Amsterdam: Elsevier.

Barfield, W., Zeltzer, D., Sheridan, T., \& Slater, M. (1995). Presence and performance within virtual environments. In W. Barfield \& T. A. Furness (Eds.), Virtual environments and advanced interface design. New York: Oxford University Press.

Battarbee, K. (2003). Defining co-experience. Proceedings of the International Conference on Designing Pleasurable Products and Interfaces, 109-113.

Battarbee, K., \& Mattelmäki, T. (2002). Meaningful product relationships. Proceedings of Third Conference of Design and Emotion.

Bruner, J. (1973). Going beyond the information given. New York: Norton.

Carey, J. M., \& Kacmar, C. J. (1997). The impact of communication mode and task complexity on small group perfor- mance and member satisfaction. Computers in Human Behavior, 13(1), 23-49.

Davenport, T. H., \& Prusak, L. (1997). Information ecology: Mastering the information and knowledge environment. New York: Oxford University Press.

Draper, V. D., Kaber, D. B., \& Usher, J. M. (1998). Telepresence. Human Factors, 40(3), 354-375.

Fiore, S. M., \& Salas, E. (2004). Why we need team cognition. In E. Salas \& S. M. Fiore (Eds.), Team cognition: Understanding the factors that drive process and performance (pp. 235-248). Washington, DC: American Psychological Association.

Flach, J. M., \& Holden, J. G. (1998). The reality of experience: Gibson's way. Presence: Teleoperators and Virtual Environments, 7, 78-89.

Flannery, K., \& Walles, R. (2003). How does schema theory apply to real versus virtual memories? Cyberpsychology \& Behavior, 6(2), 151-159.

Fontaine, G. (1992). The experience of a sense of presence in intercultural and international encounters. Presence: Teleoperators and Virtual Environments, 1, 482-490.

Forlizzi, J., \& Battarbee, K. (2004). Understanding experience in interactive systems. Proceedings of the 2004 ACM Conference on Designing Interactive Systems, 261-268.

Gabbard, J., Hix, D., \& Swan, J. E., II. (1999). User-centered design and evaluation of virtual environments. IEEE Computer Graphics and Applications, 19(6), 51-59.

Harvey, M. A, \& Sanchez-Vives, M. V. (2005). The binding problem in presence research. Presence: Teleoperators and Virtual Environments, 14(5), 616-621.

Heeter, C. (1992). Being there: The subjective experience of presence. Presence: Teleoperators and Virtual Environments, 1(2), 262-271.

Held, R., \& Durlach, N. (1992). Telepresence. Presence: Teleoperators and Virtual Environments, 1(1), 109-112.

Hunt, R., \& Ellis, H. D. (1974). Recognition memory and degree of semantic contextual change. The Journal of Experimental Psychology, 103, 1153-1159.

IJsselsteijn, W. A., \& Riva, G. (2003). Being there: The experience of presence in mediated environments. In G. Riva, F. Davide, \& W. A. IJsselsteijn (Eds.), Being there: Concepts, effects and measurement of user presence in synthetic environments. Amsterdam: IOS Press.

Lee, K. M. (2004). Why presence occurs: Evolutionary psychology, media equation, and presence. Presence: Teleoperators and Virtual Environments, 13(4): 494-505.

Lombard, M., \& Ditton, T. (1997). At the heart of it all: The concept of presence. Journal of Computer-Mediated 
Communication, 3(2). Available at http://www.ascusc. org/jcmc/vol3/issue2/lombard.html.

Lombard, M., Reich, R., Grabe, M. E., Bracken, C., \& Ditton, T. (2000). Presence and television: The role of screen size. Human Communication Research, 26, 75-98.

Ma, R. (2002). Telepresence and performance in an immersive virtual environment and sporting task. Unpublished thesis, North Carolina State University, Raleigh, NC.

Mandler, G. (1980). Recognizing: The judgment of previous occurrence. Psychological Review, 87, 252-271.

Mania, K., Robinson, A., \& Brandt, K. (2005). The effect of memory schemas on object recognition in virtual environments. Presence: Teleoperators and Virtual Environments, 14(5), 606-615.

Mantovani, G., \& Riva, G. (1999). "Real” presence: How different ontologies generate different criteria for presence, telepresence, and virtual presence. Presence: Teleoperators and Virtual Environments, 8(5) 540-550.

Neisser, U. (1976). Cognition and reality. San Francisco: Freeman.

Nunez, D. (2003). A connectionist explanation of presence in virtual environments. Master's thesis. Department of Computer Science, University of Cape Town, South Africa.

Nunez, D., \& Blake, E. (2003). Conceptual priming as a determinant of presence in virtual environments. Proceedings of the Second International Conference on Computer Graphics, Virtual Reality, Visualisation and Interaction.

Patricio, L., Falcão e Cunha, J., Fisk, R. P., \& Jardim Nunes, N. (2004). Customer experience requirements for multiplatform service interaction: Bringing services marketing to the elicitation of user requirements. Proceedings of the Twelfth IEEE International Requirements Engineering Conference.

Pine, J., \& Gilmore, J. (1999). The experience economy. Boston: Harvard Business School Press.

Revonsuo, A., \& Newman, J. (1999). Binding and consciousness. Consciousness and Cognition, 8, 123-127.

Sacau, A., Gouveia, L. M. B., Ribeiro, N. M., Gouveia, F. R., \& Biocca, F. (2003). Presence in computer-mediated environment: A short review of the main concepts, theories, and trends. Proceedings of IADIS International Conference.
Sanchez-Vives, M. V., \& Slater, M. (2005). From presence to consciousness through virtual reality. Nature Reviews Neuroscience, 6(4), 332-339.

Sas, C., \& O’Hare, G. M. P. (2005). Presence equation: An investigation into cognitive factors underlying presence. Presence: Teleoperators and Virtual Environments, 12(5), 523-537.

Schmitt, B. (2003). Customer experience management. New York: The Free Press.

Sheridan, T. B. (1992). Musings on telepresence and virtual presence. Presence: Teleoperators and Virtual Environments, l(1), 120-125.

Schuemie, M. J., van der Straaten, P., Krijn, M., \& van der Mast, C. A. P. G. (2001). Research on presence in virtual reality: A survey. Cyber Psychology \& Behavior, 4(2), 183200

Schank, D. A., \& Abelson, R. (1977). Scripts, plans, goals, and understanding. Hillsdale, NJ: Lawrence Erlbaum.

Slater, M. (2002a). Do avatars dream of digital sheep? Virtual people and the sense of presence. Proceedings of the IEEE Virtual Reality.

Slater, M. (2002b). Presence and the sixth sense. Presence: Teleoperators and Virtual Environments, 11(4), 435-439.

Slater, M., Guger, C., Edlinger, G., Leeb, R., Pfurtscheller, G., Antley, A., et al. (2006). Analysis of physiological responses to a social situation in an immersive virtual environment. Presence: Teleoperators and Virtual Environments, 15(5), 553-569.

Tscheligi, M. (2005). What else? People, disciplines, contexts, stories, occurrences. Interactions, 12(2), 62-63.

Tulving, E. (1983). Elements of episodic memory. Oxford, UK: Oxford University Press.

Witmer, B., \& Singer, M. J. (1998). Measuring presence in virtual environments: A presence questionnaire. Presence: Teleoperators and Virtual Environments, 7(3), 225-240.

Yerkes, R. M., \& Dodson, J. D. (1908). The relation of strength of stimulus to rapidity of habit-formation. Journal of Comparative Neurology and Psychology, 18, 459-482.

Zahoric, P., \& Jenison, R. L. (1998). Presence as being-inthe-world. Presence: Teleoperators and Virtual Environments, $7(1), 78-89$. 